\title{
Original solution for a photovoltaic installation at a remote site
}

\author{
Meriem CHADEL ${ }^{1,2, *}$, Moustafa Mohammed BOUZAKI ${ }^{1,2}$, Boumediene \\ BENYOUCEF ${ }^{1}$, Asma CHADEL ${ }^{1}$, Michel AILLERIE ${ }^{2,3}$, \\ ${ }^{1}$ University of Tlemcen, URMER, Tlemcen, Algeria \\ ${ }^{2}$ Université de Lorraine, LMOPS-EA 4423, 57070 Metz, France \\ ${ }^{3}$ CentraleSupelec, LMOPS, 57070 Metz, France \\ *Correspondingauthor: e-mail: ch_meriem_ph@yahoo.fr
}

Keywords: Generator PV, Solar Radiation, Power, Temperature, Series and Parallels Resistances

\begin{abstract}
We study a solution for photovoltaic plants located in an isolated site in the aim to minimize losses in PV panels due to the effect of temperature changes and intensity irradiation variations. The influence of the temperature of the solar cells is an important focus in research. We can say that the temperature has a detrimental effect on the characteristics of the solar cell. When photons of low energy are lost, there will be a loss of light output. Pmax is proportional to intensity irradiation. The series resistances reduce the efficiency of the solar cell which is not preferable. The parallel resistors increase the efficiency of the solar cell which is preferable.
\end{abstract}

\section{Introduction}

The photovoltaic energy is one of the fundamental renewable energy due its easy availability [1]. The solar cell is the electrical generator for an installation PV standalone and the connected in the network [2].

The solar cells are generally associated in series and in parallel and then encapsulated to obtain a photovoltaic module [3]. A PV array consists of modules interconnected to unit producing high continuous power compatible with the usual electrical equipment. Photovoltaic modules are usually connected in series-parallel to increase the voltage and current at the output of the generator.

The I-V characteristic of the GPV depends on the level of illumination and the cell temperature and of the aging of the assembly [2]. In addition, its operating point of the GPV directly depends on the load it supplies. To extract every moment the maximum power available across the GPV.

\section{Modeling of solar panel}

The characteristic I-V of a photovoltaic generator is based on the same principle of a solar cell that was modeled by the equivalent circuit in Figure 1 [4,5]. This circuit introduces a current source [6], a diode in parallel and series resistances Rs, parallel (shunt) Rsh to account for dissipative phenomena at the cellular level.

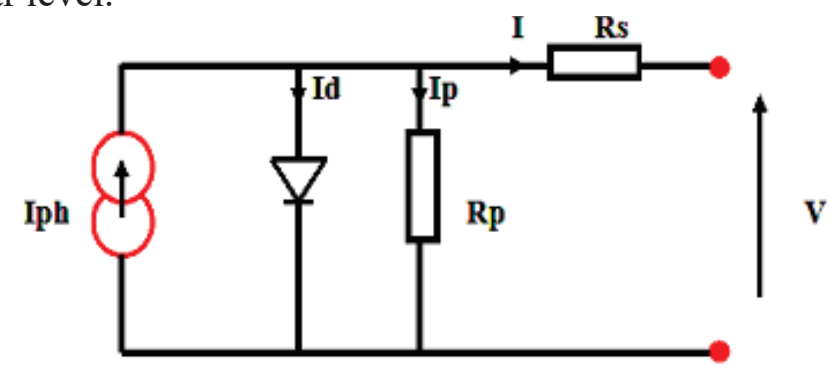

Fig. 1: Circuit equivalent of a photovoltaic cell. 
The series resistance is due to the contribution of the base resistances and the front of the junction and contacts the front and rear. Parallel resistance realizes effects such as the current losses through the edges of the cell, it is reduced by the penetration of metal impurities in the junction (especially if this penetration is deep) [7]. This circuit can be used both for a unit cell), for a module or a panel made up of several modules.

$$
I=I_{p h}-I_{0}\left(e^{\frac{q}{n K T}\left(V+R_{S} I\right)}-1\right)-\frac{V+R_{S} I}{R_{p}}
$$

Where: $\mathrm{I}_{\mathrm{ph}}, \mathrm{I}_{0}$ respectively the photo- current, the reverse saturation current of the diode and thermal stress with: $\mathrm{n}$ the ideality factor of the diode , $\mathrm{q}$ the electron charge , $\mathrm{k}$ is Boltzmann's constant, $\mathrm{T}$ the temperature of the cell which varies in function of the illumination and the ambient temperature. $\mathrm{I}_{\mathrm{Rp}}=\mathrm{I}_{\mathrm{sh}}$

$$
\begin{aligned}
& I_{0}=\frac{I_{c c}-\left(V_{c o} / R_{p}\right)}{e^{\frac{q}{n K T}\left(V+R_{S} I\right)}} \\
& I_{d}=I_{0}\left(e^{\frac{q}{n K T}\left(V+R_{S} I\right)}-1\right. \\
& I_{R p}=\frac{V+R_{S}}{R_{p}} \\
& I=I_{p h}-I_{d}-I_{R p}
\end{aligned}
$$

\section{Results of the simulation and validation of the model}

\section{Effects of irradiation in the characteristic IV}

First, we will present the results of the simulation of a solar panel with the following values of resistances series and parallelRs $=0.01 \Omega$ and $\mathrm{Rp}=1000 \Omega$.

When the illumination increases, the intensity of the photovoltaic current rises, the I-V curves shift to increasing values for the module to produce a larger electrical power. The current-voltage characteristic of the module shows a maximum power point voltage which is between 0.6 and 1.2 Volts at $25^{\circ} \mathrm{C}$.

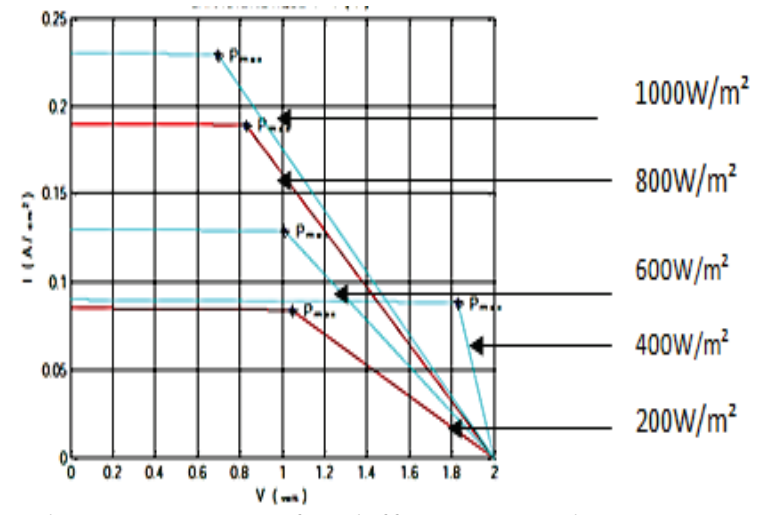

Fig2: IV characteristic of a different irradiation a Module PV.

When the radiation level is high generation of electron hole pairs will be important to increase the intensity of the current produced by the panel that is clear in the figure 2 . 
For each curve, the value of $\mathrm{I}$ is constant at the beginning in more or less different intervals', however, it will decrease in order to achieve the value of the $\mathrm{V}_{\mathrm{CO}}$.

The current (I) is inversely proportional to voltage $\mathrm{V}$.

With the increase in the value irradiation, the coordinates $(\mathrm{Im}, \mathrm{Vm})$ of the workings of the points shift to higher values, the same for Pmax (maximum power).

\section{2. $\quad$ Characterization I-V for Different Temperatures}

The temperature of the junction is proportional to the surface temperature of the solar cells.

The influence of temperature on the characteristic $I=f(V)$ (Fig. 3) is low when the junction is a same as ambient temperature. The variation becomes significant if the temperature of the junction increases.

The influence of temperature on the characteristic quantities of the cell becomes significant when the temperature of the junction different of the ambient temperature [3].

The solar flux and encapsulation of cells causes an increase in the temperature of the junction. When cells operate at high junction temperatures, they lose their characteristics and aging rapidly.

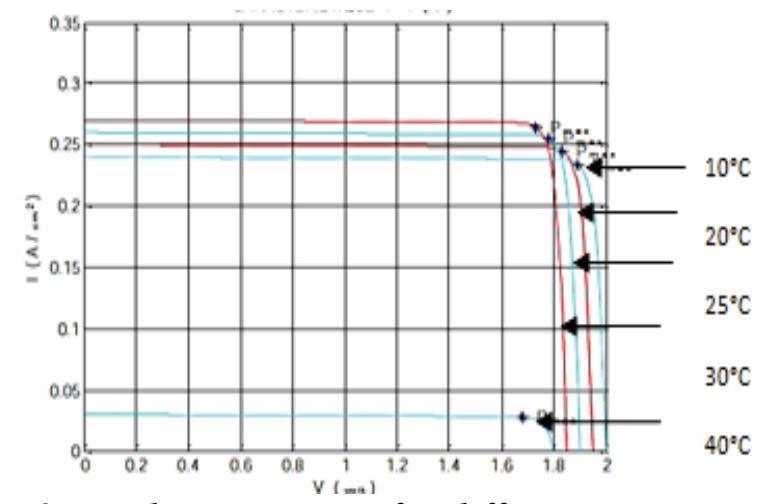

Fig 3: IV characteristics for different temperatures

It is clear that when changing the temperature varied from the junction to higher values, there will be a slight increase in short circuit current. The curves intersect with an insignificant decrease in the values of the $\mathrm{V}_{\mathrm{CO}}$.

For each curve, the value of $I$ is constant at the beginning, however, it will decrease in order to achieve the value of the $\mathrm{V}_{\mathrm{CO}}$.

\section{3. $\quad$ Characteristic IV for Different Resistances Series}

Resistance series characterise the losses by Joule effect of the resistance of the semiconductor and losses through the collection grids and bad Ohmic contacts of the cell. The influence of Rs on the characteristics of a cell is very important to the high polarization levels (near Vco) (Fig. 4).

Current technology tries to minimize the $\mathrm{R}_{\mathrm{S}}$ value by control of the illuminated region, the geometry of the cell and the concentration of impurities. The cells currently marketed Si generally have series resistances: $\mathrm{Rs}=0.01 \Omega-0.2 \Omega$.

To: $\mathrm{VCO}=1.75 \mathrm{v}$ And $\mathrm{ICC}=0.15 \mathrm{~A}$. 


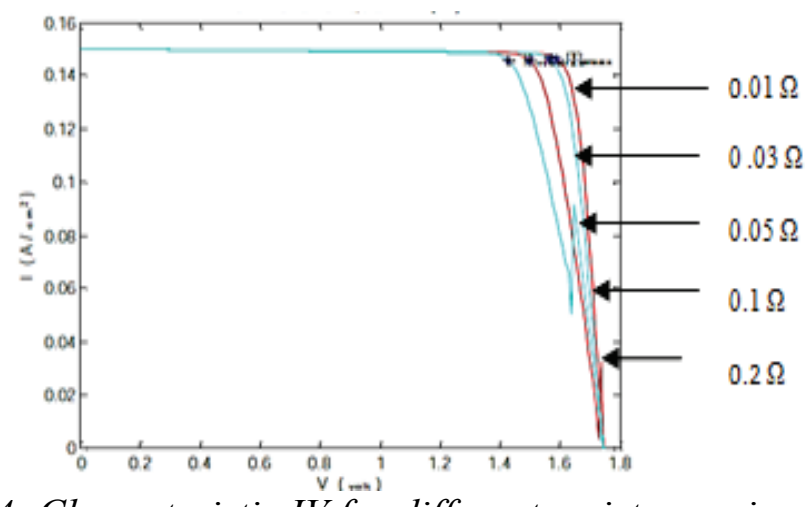

Fig 4: Characteristic IV for different resistances in series.

It is clear that when changing the resistance Rs to higher values, the short-circuit current and open circuit voltage remain constant, there will be a slight operating point decrease (reduction in maximum power)

The current I is inversely proportional to V(Fig. 4).

\section{4. $\quad$ Characteristic I-V for Different Resistances Shunt}

The parallel resistance (or shunt) characterised recombination losses due to the thicknesses of the regions $\mathrm{P}$ and $\mathrm{N}$ and the load area and space.

$\mathrm{Rp}$ is linked directly to the manufacturing process, the existence of defect structures and surface states. Rp also affects the characteristic I $=\mathrm{F}(\mathrm{v})$ its influence is very important for low bias levels (near Icc). The cells currently marketed If generally have a parallel resistance $\mathrm{Rp}=10^{2} \Omega-10^{4} \Omega$.

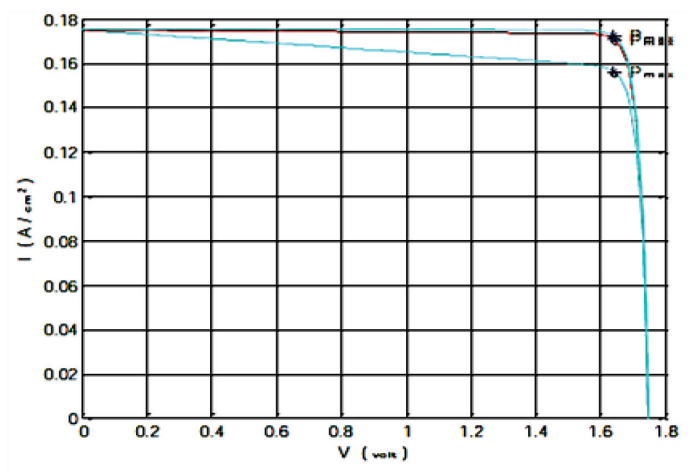

Fig 5: I-V Characteristics of a module for variation $R_{p}$.

With the increase of $\mathrm{Rp}$ value the coordinates of the Maximum power point shift to higher values, the same for Pmax.

It is clear that when changing the resistance Rp to higher values, the short -circuit current and open circuit voltage remain constant, it will increase MPP (increase in maximum power).

The current I is inversely proportional to $\mathrm{V}$ (figure 5 ).

\section{Conclusion}

In this paper, the impact of temperature, irradiation and resistance series-parallel on the performance of a PV generator were studied.

The maximum power of a solar panel is related to the amount of light it receives; that is to say, the number of photons that can set an excitation to form electron hole pairs. When photons of low energy are lost, there will be a loss of light output. Pmax is proportional to intensity irradiation.

The influence of the temperature of the solar cells is one of the important researches. Increasing the temperature of the junction is due to exposure of the latter to the sun which affects performance. We can say that the temperature has an adverse effect on the characteristics of the solar cell. The 
series resistances reduce the power of the solar cell which is not preferable. The parallel resistances increase the efficiency of the solar cell which is preferable.

\section{References}

[1] M. El Ouariachi et al, Analysis, optimization and modeling of electrical energies produced by the panels and systems, Revue des energies renouvelables, Vol $14 \mathrm{~N}^{\circ} 4$, 2011, page 707-716.

[2] Series resistance effects on solar cell measurements Advanced Energy Conversion, Vol 3, pp, 455-479.

[3] Subhash Chander et al, Impact of temperature on performance of series and parallel connected mono-crystalline silicon solar cells, Energy reports 1 (2015) 175-180.

http://dx.doi.org/10.1016/j.egyr.2015.09.001

[4] Han, L., Koide, N., Chiba, Y., \&Mitate, T. (2004). Modeling of an equivalent circuit for dyesensitized solar cells. Applied Physics Letters, 84(13), 2433-2435.

http://dx.doi.org/10.1063/1.1690495

[5] Koide, N., Islam, A., Chiba, Y., \& Han, L. (2006). Improvementofefficiencyofdye-sensitized solar cells based on analysis of equivalent circuit. Journal of Photochemistry and Photobiology

[6] A: chemistry, 182(3), 296-305.

[7] Meriem Chadelet al., Study of a photovoltaic system connected to the network with different technologies the panel PV centred, IJAER, Volume 10, Number 18 (2015),pp 38931-38936.

[8] M. Sabry, Influence of temperature on methods for determining silicon solar cell series resistance, solar research department PV laboratory, journal of solar energy engineering, Vol 129, 2007. 